\title{
RETROSPECTIVE ANALYSIS OF CAUSES OF DEATH IN HIV INFECTED PATIENTS IN IMPHAL, MANIPUR, NORTH EASTERN PART OF INDIA
}

\author{
Kh. Lokeshwar Singh ${ }^{1}$, Ksh. Achouba Singh ${ }^{2}$, M. Umakanta Singh ${ }^{3}$
}

${ }^{1}$ Associate Professor, Department of Medicine, Jawaharlal Nehru Institute of Medical Sciences (JNIMS), Imphal, Manipur. ${ }^{2}$ Associate Professor, Department of Endocrinology, Jawaharlal Nehru Institute of Medical Sciences (JNIMS), Imphal, Manipur. 3Senior Resident, Department of Medicine, Jawaharlal Nehru Institute of Medical Sciences (JNIMS), Imphal, Manipur.

\begin{tabular}{l}
\hline ABSTRACT \\
BACKGROUND AND OBJECTIVE \\
Manipur is a state located in North Eastern part of India with a huge burden of people living with HIV/AIDS. Studies of cause of \\
death in this group of people is of utmost importance to determine the preventive strategies and to derive prognosis and to compare \\
with trends in other parts of India and World. This study was conducted among the patients who were admitted to JNIMS Hospital.
\end{tabular}

\section{DATA AND METHODS}

A retrospective review of causes of death was undertaken among HIV-infected patients who were admitted between January 2010 and February 2015 at Jawaharlal Nehru Institute of Medical Sciences, Imphal, Manipur, India. Reported causes of death were coded as per the guidelines of the International Classification of Diseases (ICD-10) to establish the cause of deaths to standard definitions.

\section{RESULTS}

Of the 1524 deaths registered over a period of 62 months, 249 deaths were HIV patients. Respiratory causes accounts for majority (35\%), Hepatic causes including Hepato-Renal syndrome constitute 27\%, Central Nervous System involvement excluding Tubercular meningitis were $14 \%$.

\section{DISCUSSION}

Opportunistic infections were the major (42.57\%) cause of death. Of the total number of deaths, $76 \%$ of them were male and $57 \%$ were from urban area; $55.8 \%$ of all deaths were having CD4 count less than 250.

\section{KEYWORDS}

Cause of Death, HIV, Opportunistic Infections, JNIMS, Manipur, India.

HOW TO CITE THIS ARTICLE: Singh KL, Singh KA, Singh MU. Retrospective analysis of causes of death in HIV infected patients in Imphal, Manipur, North Eastern part of India. J. Evolution Med. Dent. Sci. 2016;5(68):4891-4896, DOI: 10.14260/jemds/2016/1112

\section{INTRODUCTION}

Study of the cause of death among HIV infected people is important to determine the preventive strategies in relation to specific disease conditions and to establish the prognostic parameters in HIV infected individuals. WHO reported 36.7 million people living with HIV/AIDS worldwide in 2015 and 1.1 million people died of AIDS-related illnesses worldwide in 2015.1

National adult (15-49 years) HIV prevalence is estimated at $0.26 \%(0.22 \%-0.32 \%)$ in 2015 . In 2015 , adult HIV prevalence is estimated at $0.30 \%$ among males and at $0.22 \%$ among females. Among the states/UTs in 2015, Manipur has shown the highest estimated adult HIV prevalence of $1.15 \%$ followed by Mizoram (0.80\%), Nagaland (0.78\%), Andhra Pradesh and Telangana (0.66\%), Karnataka (0.45\%), Gujarat $(0.42 \%)$ and Goa $(0.40 \%){ }^{2}$ Since 2007 , when the number of AIDS Related Deaths (ARD) started to show a declining trend, the annual number of AIDS related deaths has declined by 54\%. In 2015 an estimate around 67.6 thousand people died

Financial or Other, Competing Interest: None.

Submission 02-08-2016, Peer Review 15-08-2016,

Acceptance 17-08-2016, Published 24-08-2016.

Corresponding Author:

Dr. Ksh. Achouba Singh,

Uripok Bachaspati Maning Leikai,

Imphal-795001, Manipur.

E-mail: drachoubasingh@yahoo.com

DOI: $10.14260 /$ jemds/2016/1112 of AIDS-related causes nationally. This decline is consistent with the rapid expansion of access to ART in the country. It is estimated that the scale-up of free ART by Government of India since 2004 has saved cumulatively around 4.5 lakhs lives in India until 2014. ${ }^{2}$ There are very few studies done on finding out the causes of death among HIV-infected individuals in India $3,4,5$ and no studies were produced from this part of India where HIV prevalence is estimated to be highest. Therefore, this study was taken up to know the causes of death among HIV infected patients to individualise disease specific management.

\section{MATERIALS AND METHODS \\ Data}

A retrospective review of the Medical Records of those patients admitted to the Department of Medicine, Jawaharlal Nehru Institute of Medical Sciences (JNIMS), Imphal, were undertaken over a period of 62 months from January 2010 to February 2015. A total of 249 deaths were registered in relation to HIV related causes out of 1524 deaths registered in this period. A systematic master chart was prepared by entering the details and it was checked and cross-checked by various doctors separately. The causes of death were classified by using International Classification of Diseases (ICD-10) that includes a single or a combination of causes of death. Further, they were categorised into ten major domains as follows. 


\section{Cardiovascular}

Purely cardiovascular related causes, which lead to the death of the patients were categorised in this group, which includes Acute Coronary Syndrome (ACS), Congestive Cardiac Failure (CCF) and Cardiomyopathy confirmed by suitable investigations.

\section{Respiratory}

Causes of death which were due to respiratory diseases or conditions were clubbed in this category. This includes Pulmonary tuberculosis, Pneumocystis Carinii Pneumonia (PCP), Acute Respiratory Distress Syndrome (ARDS), Fungal pneumonia and Bacterial pneumonia.

\section{Renal}

Deaths due to Acute Kidney Injury (AKI/ARF) and Chronic Renal Failure (CRF) were grouped separately. We had taken only those patients whose serum creatinine level were more than 3 folds.

\section{Hepatic Causes}

Patients whose death were due to liver related conditions were included in this group. It encompasses cirrhosis of liver with/without upper gastrointestinal bleed, alcoholic liver disease, hepatic failure and hepato-renal syndrome.

\section{Central Nervous System}

Deaths due to central nervous system involvement were categorised separately. This includes Cryptococcal meningitis, Toxoplasmosis, Guillain-Barré syndrome, Pyogenic meningitis, Cytomegalovirus encephalitis, Progressive multifocal leucoencephalopathy, Hypertensive stroke (Ischaemic/haemorrhagic) and Communicating hydrocephalus; however, we had excluded Tubercular meningitis to group into extrapulmonary tuberculosis.

\section{Gastrointestinal}

Acute gastroenteritis related deaths were categorised separately.

\section{Other Opportunistic Infections}

Opportunistic infection related death among these HIV related deaths, which were not categorised in the above systems were included in here. This comprises Disseminated/ Extrapulmonary tuberculosis and Penicilliosis.

\section{Haematological}

Pancytopenia, Severe Anaemia with/without multi-organ failure and Lymphoma related deaths were categorised separately.

\section{Other Systemic Infections}

Death due to Septicemia and Scrub typhus were grouped in this category.

\section{Miscellaneous}

In this group we have included deaths due to Ruptured ectopic pregnancy, Toxic epidermal necrolysis, Acute pancreatitis, Hollow viscus perforation, Bacterial peritonitis and unknown cause.

\section{Ethical Considerations}

The Ethical Committee of Jawaharlal Nehru Institute of Medical Sciences, Imphal had given clearance to this study as it being a retrospective study, adverse events related complications are excluded. However, strict confidentiality were maintained as per guideline given by the committee.

\section{Statistical Analysis}

Descriptive statistics were calculated with mean and standard deviation for variables that were normally distributed; the median and average were calculated for variables which are distributed uniformly. To compare proportions and to interpret various data, we have utilised simple tools like percentage. All statistical analyses were performed using Microsoft Office Excel. 6

\section{RESULT}

A total of 249 deaths were HIV related patients, out of 1524 deaths in this study period from January 2010 to February 2015 which represents a large proportion of about $16.3 \%$ of the total deaths. Among them $35 \%$ of the death in this group of people were due to Respiratory causes, closely followed by Hepatic causes constituting 27\%, Central nervous system involvement excluding TBM constitute 14\%, other opportunistic infections were $7 \%$, Haematological causes were $4 \%$, Gastrointestinal 4\%, Renal causes were 3\%, Cardiovascular $2 \%$, other systemic infections $2 \%$ and Miscellaneous causes of death were 2\% (Table 1) (Figure 1). The most common age group were 40 to 65 years constituting $53 \%$ of the total HIV related deaths (Figure 2) and this is closely followed by 25 to 40 years' age group with $42 \%$ of the deaths. A great majority of $76 \%$ were male patients (Figure 3 ) and in geographical distribution urban inhabitant were on the lead constituting $57 \%$ of the deaths (Figure 4). Majority of the patients were having CD4 count less than 250 constituting $55.8 \%$ of deaths in this study (Figure 5). Opportunistic infections separately accounts for 106 of 249 deaths, which is $42.57 \%$ representing the most common cause of death among the HIV related deaths in this study (Figure 6). Tuberculosis alone constitute $42.45 \%$ of all the opportunistic infections. HCV co-infection constitute $14 \%$ of the total 249 deaths, double co-infections with HCV and HBV were 4\%, HBV alone were very few less than $1 \%$ and remaining majority of $83 \%$ were not having such co-infections (Figure 7); $61 \%$ of the patients were on ART at the time of death, $38 \%$ of them were not on ART and less than $1 \%$ of them had unknown status of ART at the time the death occurred (Figure 8).

\begin{tabular}{|c|c|c|c|c|}
\hline $\begin{array}{c}\text { Major Causes of } \\
\text { HIV Deaths }\end{array}$ & Sub-Classifications & $\begin{array}{c}\text { Number of } \\
\text { Deaths }\end{array}$ & $\begin{array}{c}\text { ICD 10 } \\
\text { Classifications }\end{array}$ & $\begin{array}{c}\text { Total Number of } \\
\text { Deaths }\end{array}$ \\
\hline \multirow{3}{*}{ Cardiovascular } & ACS & 1 & I 21 & \multirow{2}{*}{6} \\
\cline { 2 - 4 } & CCF & 3 & I 50 & \\
\cline { 2 - 4 } & Cardiac Arrest & 2 & I 46 & \multirow{2}{*}{86} \\
\cline { 2 - 4 } Respiratory & Pulmonary TB & 23 & A 15 & B 59 \\
\cline { 2 - 4 }
\end{tabular}




\begin{tabular}{|c|c|c|c|c|}
\hline & ARDS & 14 & $\mathrm{~J} 80$ & \\
\hline & Fungal Pneumonia & 3 & B 37.1 & \\
\hline & Bacterial Pneumonia & 16 & J 15.9 & \\
\hline \multirow{2}{*}{ Renal } & CKD & 3 & N 18 & \multirow{2}{*}{8} \\
\hline & ARF/AKI & 5 & N 17 & \\
\hline \multirow{3}{*}{$\begin{array}{c}\text { Hepatic Causes } \\
\text { (Including Hepato-Renal) }\end{array}$} & $\begin{array}{l}\text { Cirrhosis of Liver with/without } \\
\text { (UGI Bleed/Alcoholic LD) }\end{array}$ & 21 & $\begin{array}{c}\text { K 74.60, I 85.11 / I } \\
85.10, \text { K } 70\end{array}$ & \multirow{3}{*}{66} \\
\hline & $\begin{array}{c}\text { Hepatic Failure/ } \\
\text { Hepatorenal Syndrome }\end{array}$ & 44 & K 72.9 / K 76.7 & \\
\hline & Hepatocellular Carcinoma & 1 & C 22.0 & \\
\hline \multirow{8}{*}{$\begin{array}{l}\text { Central Nervous System } \\
\text { (Excluding TBM) }\end{array}$} & Cryptococcal Meningitis & 23 & B 45.1 & \multirow{8}{*}{36} \\
\hline & Toxoplasmosis & 1 & B 58 & \\
\hline & GB Syndrome & 1 & G 61.0 & \\
\hline & Pyogenic Meningitis & 6 & G 00.9 & \\
\hline & CMV Encephalitis & 1 & B 25.8 & \\
\hline & $\begin{array}{l}\text { Progressive Multifocal } \\
\text { Leucoencephalopathy }\end{array}$ & 1 & A 81.2 & \\
\hline & $\begin{array}{l}\text { Hypertension with Stroke } \\
\text { (Ischaemic/Haemorrhagic) }\end{array}$ & 2 & I 10 - I 15 / G 46 & \\
\hline & $\begin{array}{l}\text { Communicating } \\
\text { Hydrocephalus }\end{array}$ & 1 & G 91.0 & \\
\hline Gastrointestinal & Gastroenteritis & 10 & A 09 & 10 \\
\hline \multirow{2}{*}{$\begin{array}{l}\text { Other Opportunistic } \\
\text { Infections }\end{array}$} & Disseminated/Extrapulmonary TB & 15 & A 17.0, A 18 & \multirow{2}{*}{17} \\
\hline & Penicilliosis & 2 & B 48.4 & \\
\hline \multirow{3}{*}{ Haematological } & Pancytopenia & 3 & D 61.81 & \multirow{3}{*}{10} \\
\hline & $\begin{array}{c}\text { Severe Anaemia with/ } \\
\text { without Multi-organ Failure }\end{array}$ & 5 & D 64.9 & \\
\hline & Lymphoma & 2 & C 81 & \\
\hline \multirow{2}{*}{ Other Systemic Infections } & Septicaemia & 3 & A 41.9 & \multirow{2}{*}{4} \\
\hline & Scrub Typhus & 1 & A 75.3 & \\
\hline \multirow{7}{*}{ Miscellaneous } & Ruptured Ectopic Pregnancy & 1 & 000 & \multirow{6}{*}{6} \\
\hline & Toxic Epidermal Necrolysis & 1 & L 51.2 & \\
\hline & Acute Pancreatitis & 1 & K 85 & \\
\hline & Hollow Viscus Perforation & 1 & P 78.0 & \\
\hline & Bacterial Peritonitis & 1 & K 65.9 & \\
\hline & Unknown & 1 & R 69 & \\
\hline & & & & Grand Total=249 \\
\hline
\end{tabular}

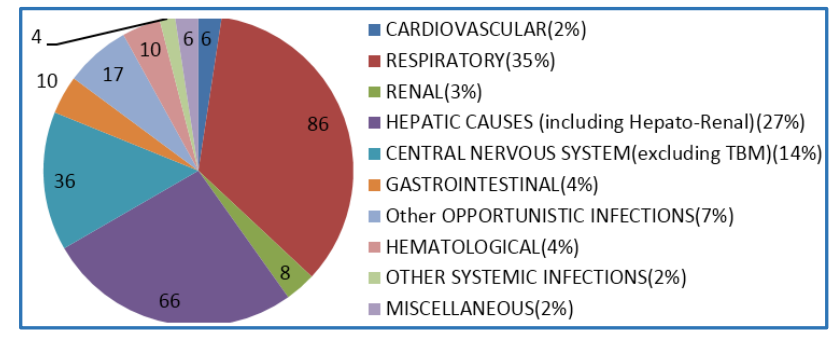

Fig. 1: Pictorial Depiction of Table 1

Among the total of 249 deaths, $35 \%$ of the death were due to Respiratory causes and closely followed by Hepatic causes constituting $27 \%$ of deaths. Central nervous system involvement excluding TBM constitute 14\%, other opportunistic infections were $7 \%$, Haematological causes were $4 \%$, Gastrointestinal $4 \%$, Renal causes were $3 \%$, Cardiovascular 2\%, other systemic infections $2 \%$ and Miscellaneous causes of death were 2\% (Figure 1).
The most common age group were 40 to 65 years constituting $53 \%$ of the total HIV related deaths and this is closely followed by 25 to 40 years' age group with $42 \%$ of the deaths; $4 \%$ of the deaths occurred in the age group 12 to 25 years and less than $1 \%$ of the deaths in age group above 65 years (Figure 2).

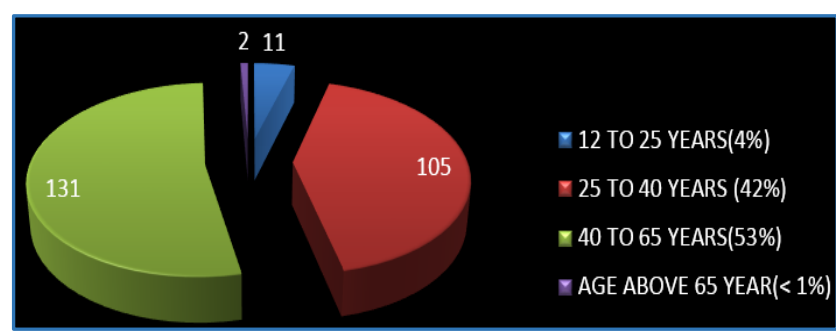

Fig. 2: Mortality in Accordance to Age Groups in Years

A great majority of $76 \%$ of the total deaths were male patients and female constitute only $24 \%$ of the deaths in this study (Figure 3). 


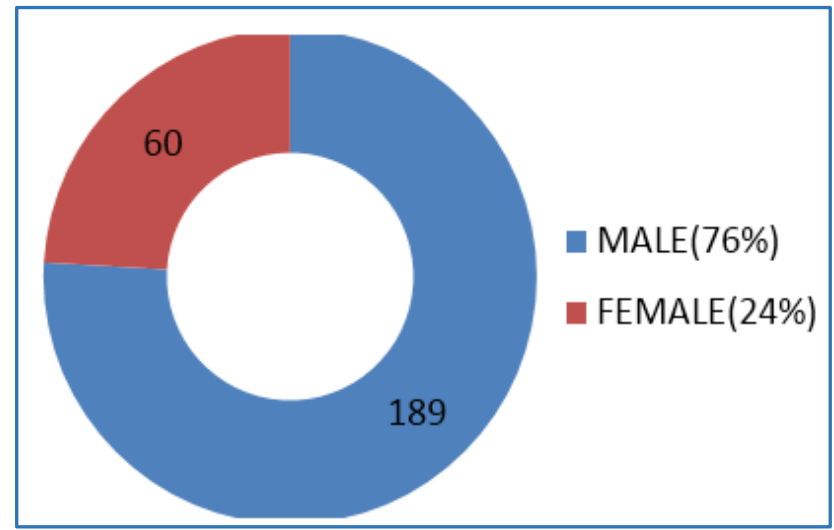

Fig. 3: Mortality Distributed according to Gender of Patients

In geographical distributions, a total of 142 deaths were urban dwellers representing 57\% and rural constitute 107 which is $43 \%$ of the HIV related deaths in this study (Figure 4 ).

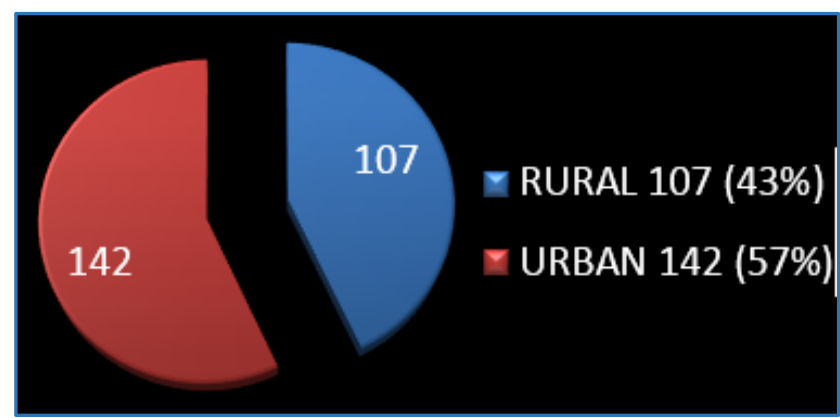

Fig. 4: Geographical Distributions of Mortality of the HIV-Related Deaths
In this study majority of the patients were having CD4 count, less than 250 constituting $55.8 \%$ of deaths, $15.6 \%$ of them were having CD4 count between 250 to 500 ; those group whose CD4 count were above 500 constitute only $2.8 \%$ of the HIV related deaths and CD 4 status of 64 patients could not be traced that accounts for about $25.7 \%$ (Figure 5).

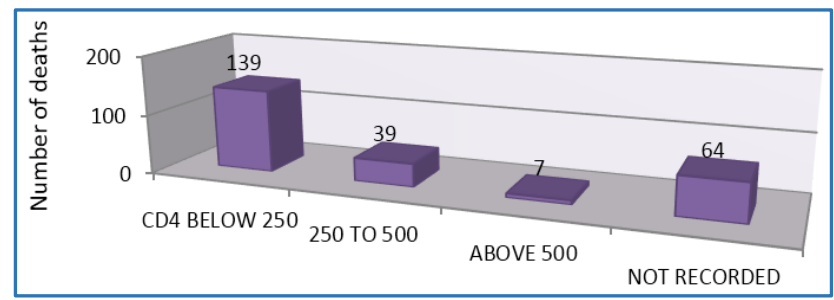

Fig. 5: Classification of Mortality According to CD4 Levels at the Time of Death

Opportunistic infections separately accounts for 106 of 249 deaths, which is $42.57 \%$ representing the most common cause of death among the HIV related deaths in this study (Figure 6). Tuberculosis alone constitute $42.45 \%$ of all the opportunistic infections. Pulmonary tuberculosis were $28.3 \%$, disseminated and extrapulmonary tuberculosis were $14.1 \%$, Pneumocystis Carinii Pneumonia (PCP) were 21.7\%, similarly cryptococcal meningitis were $21.7 \%$, gastroenteritis were 9.4\%, Penicilliosis were $1.9 \%$ and .9\% each for Toxoplasmosis, Cytomegalovirus (CMV) encephalitis and Progressive multifocal leucoencephalopathy as the causes of death among HIV death due to opportunistic infections (Figure 6).

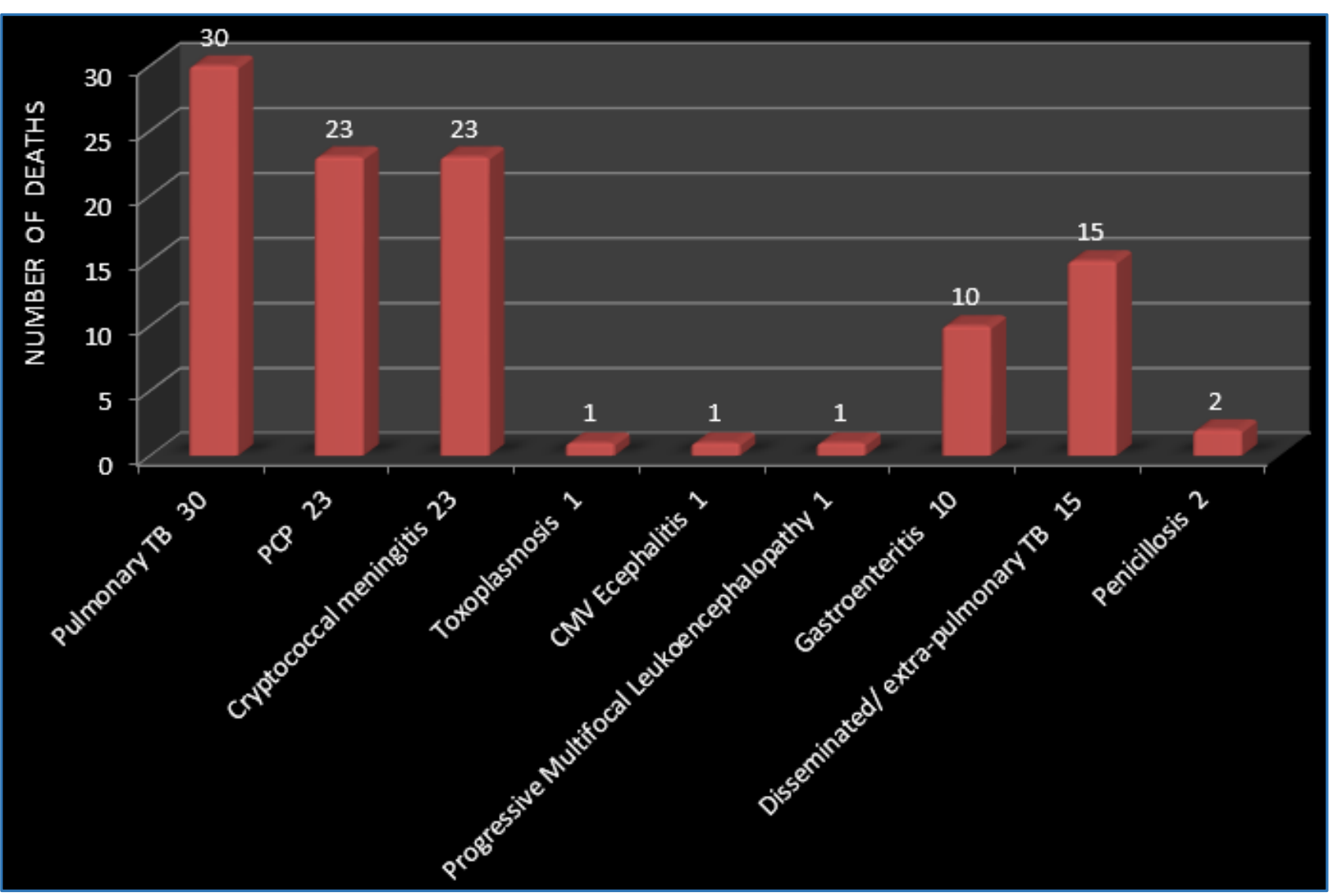

Fig. 6: Mortality Distributions According to Opportunistic Infections 
HCV co-infection constitute $14 \%$ of the total 249 deaths, double co-infections with HCV and HBV were $4 \%$, HBV alone were very few, less than $1 \%$ and remaining majority of $83 \%$ were not having such co-infections at the time of death (Figure 7).

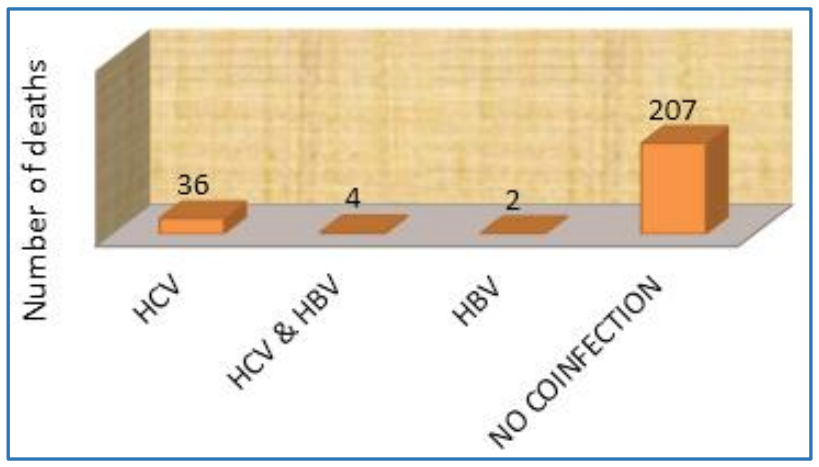

Fig. 7: Mortality According to Co-Infections

$61 \%$ of the patients were on ART at the time of death, $38 \%$ of them were not on ART and less than $1 \%$ of them had unknown status of ART at the time the death occurred (Figure 8).

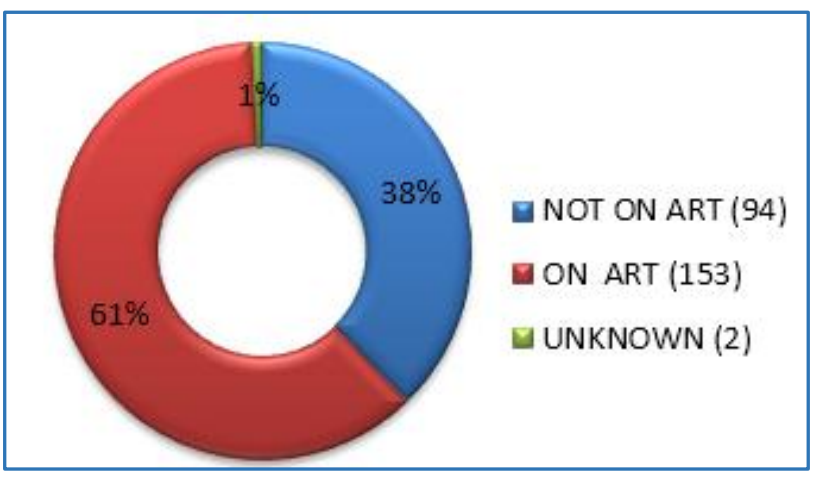

Fig. 8: Mortality According to Status of Anti-Retroviral Therapy

\section{DISCUSSION}

This study documents that $35 \%$ of the death were due to Respiratory causes showing it as the most common system causing death in HIV infected people, similar observations were also found in a study conducted in Europe. ${ }^{7}$ Hepatic causes constituting $27 \%$ of deaths making it second most common system to cause death in HIV patients; this observation is supported by a study in United States of America. ${ }^{8}$ Central nervous system involvement excluding TBM constitute $14 \%$, other opportunistic infections were $7 \%$, Haematological causes were 4\%, Gastrointestinal 4\%, Renal causes were $3 \%$, Cardiovascular $2 \%$, other systemic infections $2 \%$ and Miscellaneous causes of death were $2 \%$. These findings were supported by various studies published in other countries ${ }^{9}$ and other parts of India. $3,4,5$

The most common age group were 40 to 65 years constituting $53 \%$ of the total HIV related deaths and this is closely followed by 25 to 40 years' age group with $42 \%$ of the deaths; $4 \%$ of the deaths occurred in the age group 12 to 25 years and less than $1 \%$ of the deaths in age group above 65 years. Similar study done over eight regions of the world had similar findings of higher mortality around the age of 60 years; ${ }^{10}$ whereas a mortality study done at Pune, India, age group above 35 years had higher mortality among the HIV infected patients. This study also relates well with the present study. 4

Majority of $76 \%$ of the total deaths were male patients and female constitute only $24 \%$ of the deaths in this study, which is remarkably similar to the finding of a study conducted in Southern India. ${ }^{3}$ In geographical distributions of the deaths, urban dwellers represented $57 \%$ and rural constitute $43 \%$ of the HIV related deaths in this study. This finding may be attributed to higher number of HIV patients in urban than rural. A study done in South Africa documented similar finding. ${ }^{11}$

In this study majority of the patients were having CD4 count less than 250 constituting $55.8 \%$ of deaths, $15.6 \%$ of them were having CD4 count between 250 to 500 , those group whose CD 4 count were above 500 constitute only $2.8 \%$ of the HIV related deaths and CD 4 status of 64 patients could not be traced that accounts for about $25.7 \%$. This finding is consistent with a few studies, which highlighted that low CD4 count continues to play an important role in predicting deaths due to HIV infections. ${ }^{5,12}$

Opportunistic infections accounts for 106 of 249 deaths, which is $42.57 \%$ representing the most common cause of death among the HIV related deaths in this study. Tuberculosis alone constitute $42.45 \%$ of all the opportunistic infections. Pneumocystis jirovecii pneumonia and Cryptococcal meningitis caused $21.7 \%$ deaths each in these groups of opportunistic infections related deaths. A major article published by United States of America13 and a few studies in India3,4,5 had shown similar evidence that the opportunistic infections were the most common over all cause of HIV related deaths.

HCV co-infection were more common in this study constituting $14 \%$ of the total 249 deaths, double co-infections with HCV and HBV were $4 \%$, HBV alone were very few less than $1 \%$ and remaining majority of $83 \%$ were not having such co-infections. The co-infection pattern observed in this study were in contrast to the observation of a study done in Southern India, ${ }^{3}$ where HBV co-infection were more common than HCV co-infections.

$61 \%$ of the patients were on ART at the time of death, $38 \%$ of them were not on ART and less than $1 \%$ of them had unknown status of ART at the time the death occurred. The findings of the present study suggest that despite the wider introduction of HAART, mortality still continues to occur due to varying study populations, time frames and analytic designs or advanced immunodeficiency soon after starting therapy. $3,13,14,15,16$

\section{CONCLUSION}

This study provide a systematic review of the causes of deaths in HIV infected patients of Manipur in the Eastern region of India. It also gave knowledge about the prognostic significance and concern about the need to formulate protocol based proper management of the HIV infected patients in view of these spectrum of conditions for a better life of those people living with HIV. 


\section{REFERENCES}

1. WHO updates: http://www.who.int/gho/hiv/en/, accessed on July 21, 2016.

2. India HIV estimate by NACO 2015. http://www.naco.gov.in/upload/2015\%20MSLNS/HSS/ India\%20HIV\%20Estimations\%202015.pdf accessed on July 21, 2016.

3. Kumarasamy N, Venkatesh KK, Devaleenol B, et al. Factors associated with mortality among HIV-infected patients in the era of highly active antiretroviral therapy in southern India. International Journal of Infectious Diseases 2010;14(2):e127-31.

4. Ghate M, Deshpande S, Tripathy S, et al. Mortality in HIV infected individuals in Pune, India. Indian J Med Res 2011;133(4):414-20.

5. Bhattacharjya C, Sahu D, Patel SK, et al. Causes of death among HIV-infected adults registered in selected antiretroviral therapy centers in north-eastern India. World Journal of AIDS 2015;5(2):90-9.

6. (C)2006 Microsoft Corporation. Microsoft $₫$ Office Excel $\AA$ 2007(12.4518.1014) MSO (12.0.4518.1014) Part of Microsoft Office Enterprise 2007.

7. Benito N, Moreno A, Miro JM, et al. Pulmonary infections in HIV-infected patients: an update in the 21st century. Eur Respir J 2012;39(3):730-45.

8. Price JC, Thio CL. Liver Disease in the HIV-infected individual. Clin Gastroenterol Hepatol 2010;8(12): 1002-12.

9. Luma HN, Tchaleu BCN, Temfack E, et al. HIV-Associated central nervous system disease in patients admitted at the Douala general hospital between 2004 and 2009: a retrospective study. AIDS Research and Treatment 2013;2013:1-6.
10. Murray CJL, Lopez AD. Mortality by cause for eight regions of the world: global burden of disease study. Lancet 1997;349(9061):1269-76.

11. Otwombe KN, Petzold M, Modisenyane T, et al. Factors associated with mortality in HIV-infected people in rural and urban South Africa. Glob Health Action 2014; 7:25488.

12. Ingle SM, May MT, Gill MJ, et al. Impact of risk factors for specific causes of death in the first and subsequent years of antiretroviral therapy among HIV-infected patients. Clinical Infectious Diseases 2014;59(2):287-97.

13. Djawe K, Buchacz K, Hsu L, et al. Mortality risk after AIDSdefining opportunistic illness among HIV-infected persons-San Francisco, 1981-2012. Journal of Infectious Diseases Advance Access published 2015.

14. Dore GJ, Li Y, McDonald A, et al. Impact of highly active antiretroviral therapy on individual AIDS-defining illness incidence and survival in Australia. J Acquir Immune Defic Syndr 2002;29(4):388-95.

15. Grabar S, Lanoy E, Allavena C, et al. Causes of the first AIDS-defining illness and subsequent survival before and after the advent of combined antiretroviral therapy. HIV Med 2008;9(4):246-56.

16. Mocroft A, Sterne JA, Egger M, et al. Variable impact on mortality of AIDS-defining events diagnosed during combination antiretroviral therapy: not all AIDS-defining conditions are created equal. Clin Infect Dis 2009;48(8):1138-51. 